\title{
Identification of introgressed rice lines of Binadhan-7×FL-378 under salt stress through SSR markers
}

\author{
M. A. Haque, M. A. Mahmud, M. M. Islam ${ }^{1}$ and S. N. Begum ${ }^{2}$ \\ Department of Genetics and Plant Breeding, Bangladesh Agricultural University, Mymensingh-2202, Bangladesh, \\ ${ }^{1}$ Biotechnology Division and ${ }^{2}$ Plant Breeding Division, Bangladesh Institute of Nuclear Agriculture, Mymensingh-2202, \\ Bangladesh. E-mail: ashraf_gpb2000@yahoo.com
}

\begin{abstract}
Thirty two rice lines of $\mathrm{BC}_{1} \mathrm{~F}_{1}$ population (Binadhan-7/FL 378) were used to identify introgressed rice lines for salt tolerance using SSR markers at the Plant Breeding and Biotechnology Divisions of Bangladesh Institute of Nuclear Agriculture (BINA), Mymensingh. Seeds of $B C_{1} F_{1}$ population of Binadhan-7/FL-378 were collected from backcross population of $F_{1}$ (Binadhan-7/FL 378). Salt tolerant genotype, FL-378 was crossed with high yielding variety, Binadhan-7. Randomly selected $32 \quad \mathrm{BC}_{1} \mathrm{~F}_{1}$ progenies along with their two parents (Binadhan-7, FL-378) were genotyped with microsatellite or SSR markers for identification of introgressed rice lines. Parental polymorphism survey was assayed by 8 SSR markers and three polymorphic SSR markers viz., RM296, RM585 and OSR30 were selected to evaluate $\mathrm{BC}_{1} \mathrm{~F}_{1}$ rice lines for salt tolerance. Primer RM585 indicated 16 lines as introgressed and 16 lines as susceptible in comparison with salt tolerant parent FL-378 and salt susceptible parent Binadhan-7. Primer RM296 identified 13 introgressed, and 19 susceptible lines. Nine introgressed and 23 susceptible lines were identified when $\mathrm{BC}_{1} \mathrm{~F}_{1}$ lines were evaluated with marker OSR30. Line $\mathrm{BC}_{1} \mathrm{~F}_{1}-30, \mathrm{BC}_{1} \mathrm{~F}_{1}-40, \mathrm{BC}_{1} \mathrm{~F}_{1}-2, \mathrm{BC}_{1} \mathrm{~F}_{1}-16$ and $\mathrm{BC}_{1} \mathrm{~F}_{1}-34$ were identified as introgressed in comparison with parent FL-378 (salt tolerant) when RM585 and RM296 markers were used but line $B C_{1} F_{1}-1$ and $B C_{1} F_{1}-3$ were identified as introgressed incase of 3 primers (RM585, RM296 and OSR30). Again the lines $B C_{1} F_{1}-5, B C_{1} F_{1}-24, B C_{1} F_{1}-26, B C_{1} F_{1}-27, B C_{1} F_{1}-29, B C_{1} F_{1}-31, B C_{1} F_{1}-37$ and $B C_{1} F_{1}-38$ were found susceptible as compared with parent Binadhan-7 when marker RM585, RM296 and OSR30 were used. The polymorphism information content (PIC) values ranged from 0.3290 to 0.3671 with an average of 0.3544 . The overall gene diversity of SSR loci for the $32 \mathrm{BC}_{1} \mathrm{~F}_{1}$ rice lines along with two parents was 0.4614 , ranging from 0.4152 to 0.4844. Positive correlations were found between the genetic diversity and the maximum number of repeats. Among the lines, all the loci were polymorphic and clearly distinct and the cluster analysis (NJ tree and UPGMA) showed nearly similar pattern of variation which could be used for improvement of salt tolerant rice lines of rice through SSR markers.
\end{abstract}

Keywords: Salt stress, SSR Markers, Binadhan-7×FL-378

\section{Introduction}

Salinity is the second most widespread soil problem in rice growing countries after drought and is considered as a serious constraint to increase rice production worldwide (Gregorio, 1997). Over 800 million hectares of land throughout the world are salt-affected (FAO, 2005). In Bangladesh, saline soil covers about 2.8 million ha of land (BBS, 2009). The total saline area forms one third of the 9 million ha of total cultivated area of Bangladesh (ABSPII, 2006). The existing modern varieties are not adapted to this ecosystem because of their lack in salt tolerance. But now it becomes an essential for us to adapt modern varieties under saline environment. So development of salt tolerant rice varieties has become a demand for this country to feed the bursting population (Ashraf et al., 2008; Ashraf, 2009). The conventional methods of plant selection for salt tolerance are not easy because of the large effects of the environment and low narrow sense heritability of salt tolerance (Gregorio, 1997). However, DNA markers seem to be the best candidates for efficient evaluation and selection of plant material. DNA-based markers such as SSR markers which are co-dominant and highly polymorphic, offer an easy, accurate, and quantifiable measure of the genetic variation within crop plants (Litt and Luty, 1989 ; Tautz, 1989). SSR or microsatellite markers are proved to be ideal for making genetic maps (Islam, 2004; Niones, 2004), assisting selection (Bhuiyan, 2005) and identification of salt tolerant rice lines. Microsatellite marker analysis is promising to identify major gene locus for salt tolerance that can be helpful for plant breeders to develop new cultivars. 
The general objective of this work is to contribute to the development of salt tolerant rice variety and the specific objectives are-

1. To transfer salt tolerant gene(s) into high yielding rice variety (Binadhan-7); and

2. To identify salt tolerant rice line of $\mathrm{BC}_{1} \mathrm{~F}_{1}$ progenies of Binadhan-7× FL- 378 using SSR markers.

\section{Materials and Methods}

\section{Experimental site and plant materials}

The experiment was carried out in Plant Breeding Division, Bangladesh Institute of Nuclear Agriculture (BINA), Mymensingh from July, 2010 to September, 2011. On the basis of phenotypic and genotypic evaluation for salt tolerance, one rice genotype (FL-378) was selected as parent for transferring salt tolerant genes (Islam, 2004) from tolerant to high yielding rice variety (Binadhan-7). Several crosses were made for introgressing salt tolerant genes into popular rice variety. In this study, a backcross was made between $\mathrm{BC}_{1} \mathrm{~F}_{1}$ lines (Binadhan-7/FL-378) with high yielding Binadhan-7. Based on desired agronomic characters $58 \mathrm{BC}_{1} \mathrm{~F}_{1}$ plants were grown . But only $32 \mathrm{BC}_{1} \mathrm{~F}_{1}$ rice lines were utilized for the identification of salt tolerant lines and the genotyping was done using SSR markers.

\section{Production of seed materials}

The seeds of $\mathrm{BC}_{1} \mathrm{~F}_{1}$ line were collected and kept in the convection oven for $24 \mathrm{~h}$ at $30^{\circ} \mathrm{C}$ for germination. Among these seeds, 67 seeds were germinated and transplanted in the plastic bucket in which 58 seedlings were survived. Finally 32 seedlings were selected randomly to collect the leaf to make foreground selection genotypically at the molecular level by using SSR markers and $220 \mathrm{BC}_{2} \mathrm{~F}_{1}$ seeds were developed through successful backcrossing.

\section{Genomic DNA isolation and Polymorphism survey for primer selection}

Young vigorously growing fresh leaf samples from the seedlings of Binadhan-7, FL-378 and $\mathrm{BC}_{1} \mathrm{~F}_{1}$ population were collected to extract genomic DNA. The samples were stored in $-80^{\circ} \mathrm{C}$ freezer with marking. DNA were extracted from leaf samples following CTAB method and were stored at $-20^{\circ} \mathrm{C}$ temperature. Eight primers of random sequence were selected for amplification of the DNA sequences. Primers were evaluated based on intensity of bands, consistency within individual, presence of smearing and potentiality for population discrimination. In this experiment RM510, OSR30, RM21, RM127, RM140, RM9, RM296 and RM585 primers were used for parental survey (data not shown). Among them three polymorphic SSR markers viz., RM296, RM585 and OSR30 were selected to evaluate $\mathrm{BC}_{1} \mathrm{~F}_{1}(32)$ rice lines for salt tolerance. The sequences of the primers are given in Table 1.

Table 1. The sequence and size of the microsatellite markers used for parental and $B C_{1} F_{1}$ survey

\begin{tabular}{|c|c|c|c|c|}
\hline Primer & PCR & \multicolumn{2}{|c|}{ Sequence $\left(5^{\prime}-3^{\prime}\right)$} & \multirow{2}{*}{$\begin{array}{c}\text { Annealing } \\
\text { temp. }\end{array}$} \\
\cline { 3 - 6 } & $\begin{array}{c}\left.{ }^{\circ} \mathrm{C}\right) \\
\text { size }(\mathrm{bp})\end{array}$ & Forward & Reverse & 55 \\
\hline OSR30 & 205 & GAAACCACCACACCTCACCG & CCGTAGACCTTCTTGAAGTAG & 55 \\
\hline RM585 & 233 & CAGTCTTGCTCCGTTTGTTG & CTGTGACTGACTTGGTCATAGG & 55 \\
\hline RM296 & $164-194$ & TGGCTGGCTCCGTGGGTAGCTG & TCCCGTTGCCGTTCATCCCTCC & 67 \\
\hline
\end{tabular}

\section{Results and Discussion}

\section{Genotypic performance of backcross population $\mathrm{BC}_{1} \mathrm{~F}_{1}$ along with their two parents}

The banding patterns were scored with reference to those of FL-378 and Binadhan-7, since FL-378 is salt tolerant and Binadhan-7 is salt susceptible. In each marker, allelic bands were scored based on the parental bands (Table 2). 
Table 2. Thirty two $B C_{1} F_{1}$ populations with respect to the alleles amplified by the microsatellite primer i.e. RM296, RM585 and OSR3

\begin{tabular}{|c|c|c|c|c|}
\hline \multirow{2}{*}{$\begin{array}{c}\text { Name of } \\
\text { primers }\end{array}$} & \multirow{2}{*}{$\begin{array}{c}\text { Total no. of parental } \\
\mathrm{BC}_{1} \mathrm{~F}_{1} \text { lines }\end{array}$} & $\begin{array}{c}\text { Tolerance type } \\
(\text { FL-378) }\end{array}$ & $\begin{array}{c}\text { Susceptible type } \\
\text { (Binadhan-7) }\end{array}$ & Heterozygous \\
\cline { 3 - 5 } & \multirow{2}{*}{32} & 14 & 16 & 2 \\
\cline { 4 - 5 } RM585 & & 11 & 19 & 2 \\
\hline RM296 & & 7 & 23 & 2 \\
\hline OSR30 & & & & \\
\cline { 3 - 5 }
\end{tabular}

\section{Overall performance of $\mathrm{BC}_{1} \mathrm{~F}_{1}$ rice lines}

$\mathrm{BC}_{1} \mathrm{~F}_{1}$ rice lines showed wide variation with three primers; RM585, RM296 and OSR30. In respect of primer RM585, a total of 16 lines (14 lines were similar to donor parent type FL-378 and 2 were heterozygous) were identified (Fig.1) as introgressed lines derived from backcrossing between $F_{1}$ (Binadhan-7×FL378) and Binadhan-7.

With respect to the primer RM296, total 13 lines (11 lines were similar to parent FL-378) were identified (Fig. 2) as introgressed lines derived from backcrossing between $F_{1}$ (Binadhan-7×FL-378) and Binadhan7. Considering the primer OSR30, total 9 lines (7 lines were similar to donor parent type FL-378 and 2 were heterozygous) were identified (Fig. 3 ) as introgressed lines derived from backcrossing between $F_{1}$ (Binadhan-7×FL-378) and Binadhan-7. These three primers (RM296, OSR30 and RM585) showed polymorphisms in the studied parents and their $\mathrm{BC}_{1} \mathrm{~F}_{1}$ population because they showed different banding patterns and discriminate tolerant lines from susceptible with relation to their tolerant (FL-378) and susceptible (Binadhan-7 parents). Those markers were also reported as highly polymorphic in IR29 $\times$ Pokkali for tagging salt tolerant genes (Islam, 2004; Niones, 2004). El-Refaee et al. (2006) also reported that $80 \%$ of the all tested SSR primers showed polymorphic pattern in rice while they studied 272 SSR primers on nine rice genotypes.

\section{Allelic and loci variation within the genotypes}

Gene diversity: According to Nei's (1983), the highest level of gene diversity value (0.4844) was observed in loci RM585 and RM296; the lowest level of gene diversity value (0.4152) was observed in loci OSR30 with a mean diversity of 0.4614 (Table 3). It was observed that marker detecting the fewer alleles showed lower gene diversity than those detected higher number of alleles which revealed higher gene diversity. The maximum number of repeats within the SSRs was also positively correlated with the genetic diversity. This result is consistent with previous work done by Herrera et al. (2008), who observed that the gene diversity at each SSR locus was significantly correlated with the number of alleles detected, number of repeat motif and with the allele size range.

Allele size range: The size variation between the smallest and the largest allele at a given SSR locus was correlated with the number of alleles per locus. Thus, RM585 presented the smallest allele size range (25bp), while OSR30 presented the largest allele size range (61bp) (Table 3).

PIC values: As a measure of the informativeness of microsatellites, the PIC values ranged from a low of 0.3290 (OSR30) to a high of 0.3671 (RM585 and RM296) and averaged 0.3544 (Table 3).

Table 3. Data on allele size ranges, polymorphism information content (PIC), gene diversity found among $32 \mathrm{BC}_{1} \mathrm{~F}_{1}$ populations of Binadhan-7 $\times$ FL-378 along with their parents for 3 SSR markers

\begin{tabular}{|c|c|c|c|c|}
\hline Locus & Allele size ranges & Differences (bp) & Gene Diversity & PIC \\
\hline RM585 & $229-254$ & 25 & 0.4844 & 0.3671 \\
\hline RM296 & $214-263$ & 49 & 0.4844 & 0.3671 \\
\hline OSR30 & $235-296$ & 61 & 0.4152 & 0.3290 \\
\hline Mean & & & 0.4614 & 0.3544 \\
\hline
\end{tabular}




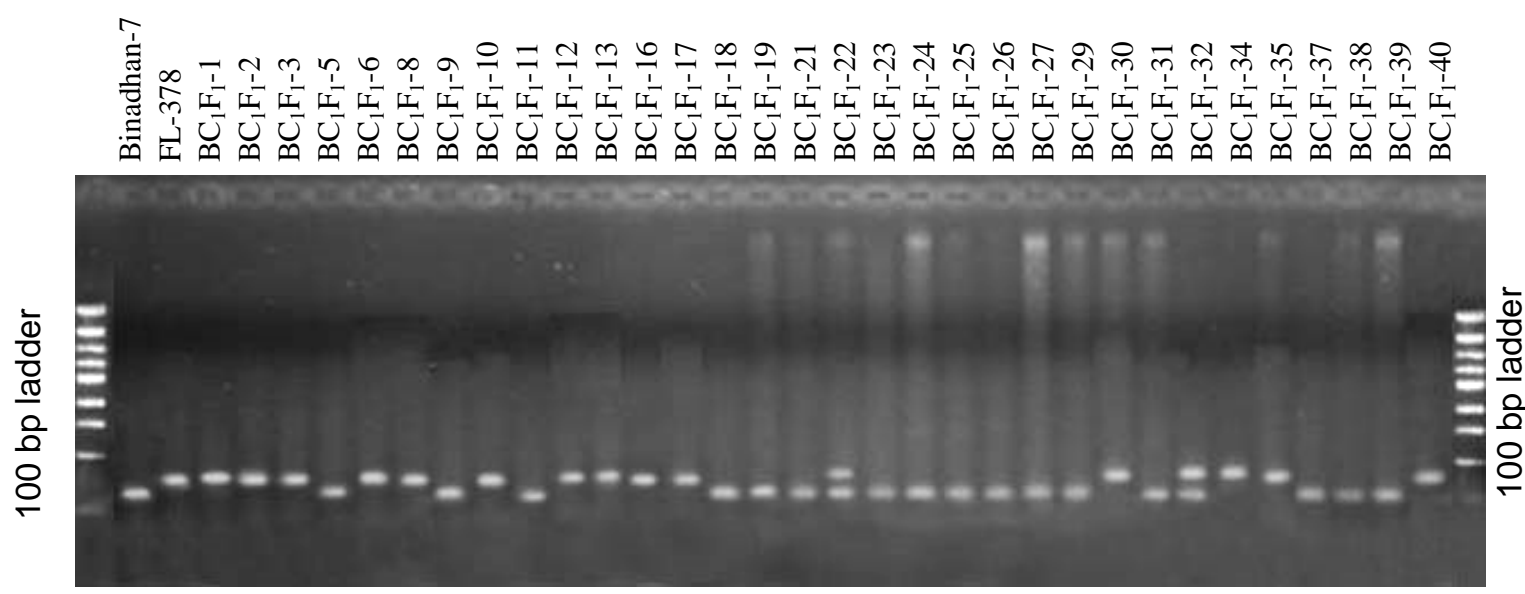

Fig. 1. Banding pattern of $B C_{1} F_{1}$ population of Binadhan-7/FL-378 using RM585

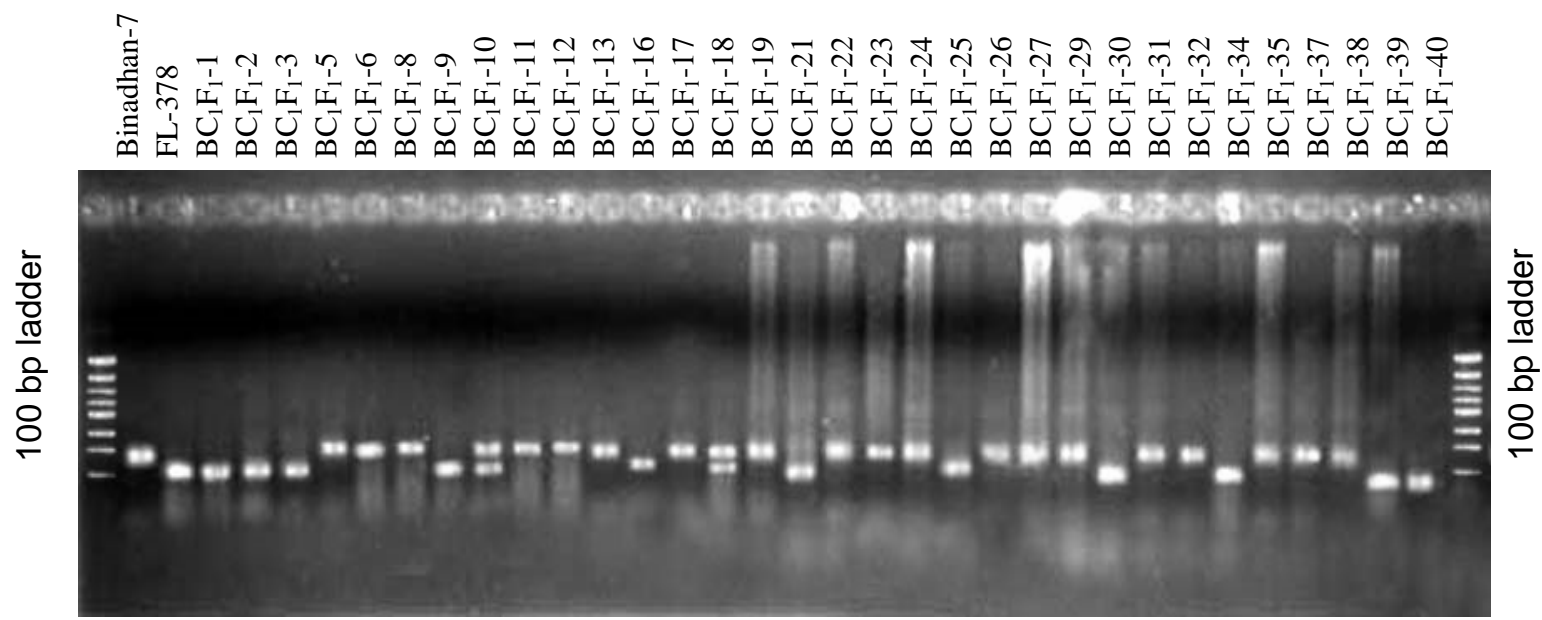

Fig. 2. Banding pattern of $B C_{1} F_{1}$ population of Binadhan-7/FL-378 using SSR marker RM296
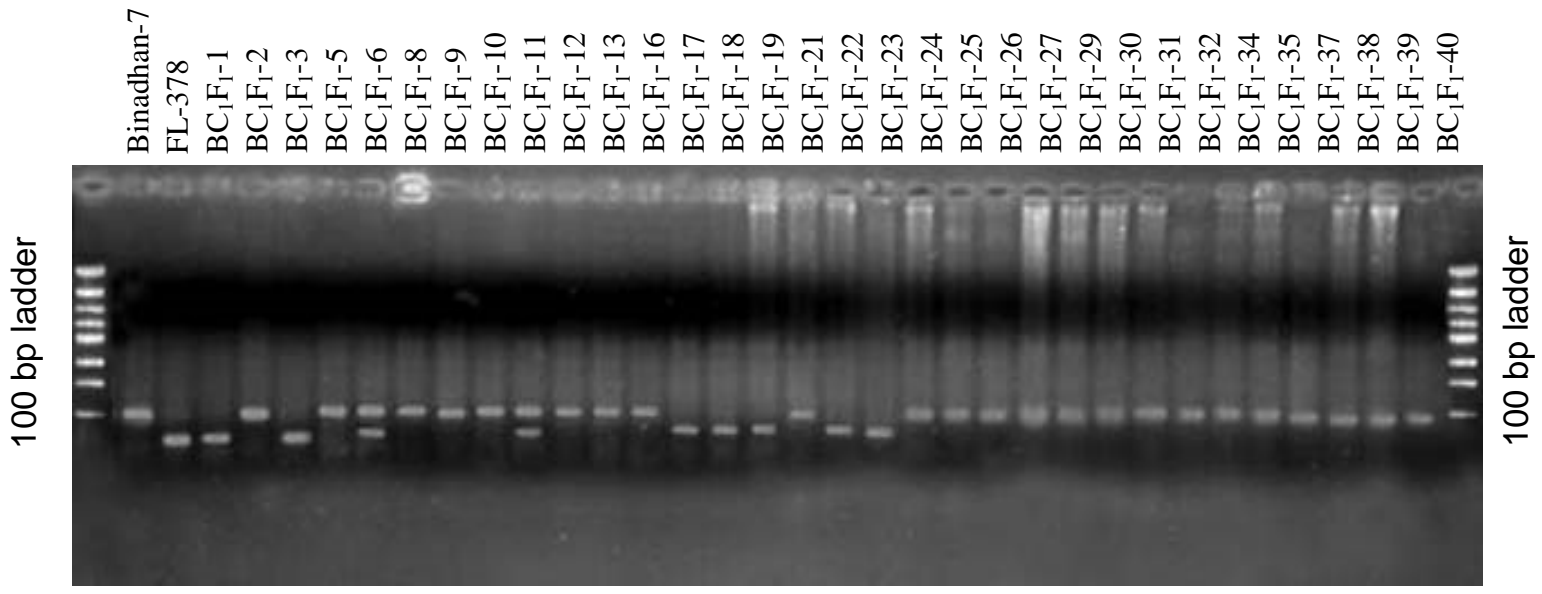

Fig. 3. Banding pattern of $B C_{1} F_{1}$ population of Binadhan-7/FL-378 using SSR marker OSR30 


\section{Genetic similarity analysis using UPGMA (Unweighted Pair Group Method of Arithmetic Means)}

A dendrogram was constructed based on the Nei's genetic distance calculated from the $32 \mathrm{BC}_{1} \mathrm{~F}_{1}$ populations of Binadhan-7 x FL-378 along with their parents. The UPGMA cluster tree analysis led to the grouping of the $32 \mathrm{BC}_{1} \mathrm{~F}_{1}$ populations of Binadhan-7 $\times \mathrm{FL} 378$ along with their parents in two major cluster (Fig. 4). In sub-cluster $2 \mathrm{~b}, \mathrm{BC}_{1} \mathrm{~F}_{1}-5$, Binadhan-7, $\mathrm{BC}_{1} \mathrm{~F}_{1}-24, \mathrm{BC}_{1} \mathrm{~F}_{1}-26, \mathrm{BC}_{1} \mathrm{~F}_{1}-27$ and $\mathrm{BC}_{1} \mathrm{~F}_{1}-29$ showed close similarity and to same sub-cluster and they were susceptible under salt stress. In sub-cluster 3 , $\mathrm{BC}_{1} \mathrm{~F}_{1}-18, \mathrm{FL}-378, \mathrm{BC}_{1} \mathrm{~F}_{1}-1$ and $\mathrm{BC}_{1} \mathrm{~F}_{1}-3$ showed close genetic distance (0.3333) lies under same subcluster and they were tolerant under salt stress i.e. they were introgressed lines. Several additional subclusters were observed within the main clusters. The dendrogram revealed that the genotypes that derivatives of genetically similar type clustered together. Chakravarti et al. (2006) classified the rice genotypes into 11 distinct groups. Cluster analysis of the 193 accessions parental lines of rice showed 3 major groups and 9 subgroups (Yu et al. 2000). Based on above result, it may be concluded that the tolerant germplasm grouped in same cluster due to lower genetic distance in comparison with FL-378. While, the susceptible germplasm grouped in same cluster due to higher genetic distance in comparison with FL-378.

\section{Dendrogram for clustering $\mathrm{BC}_{1} \mathrm{~F}_{1}$ lines}

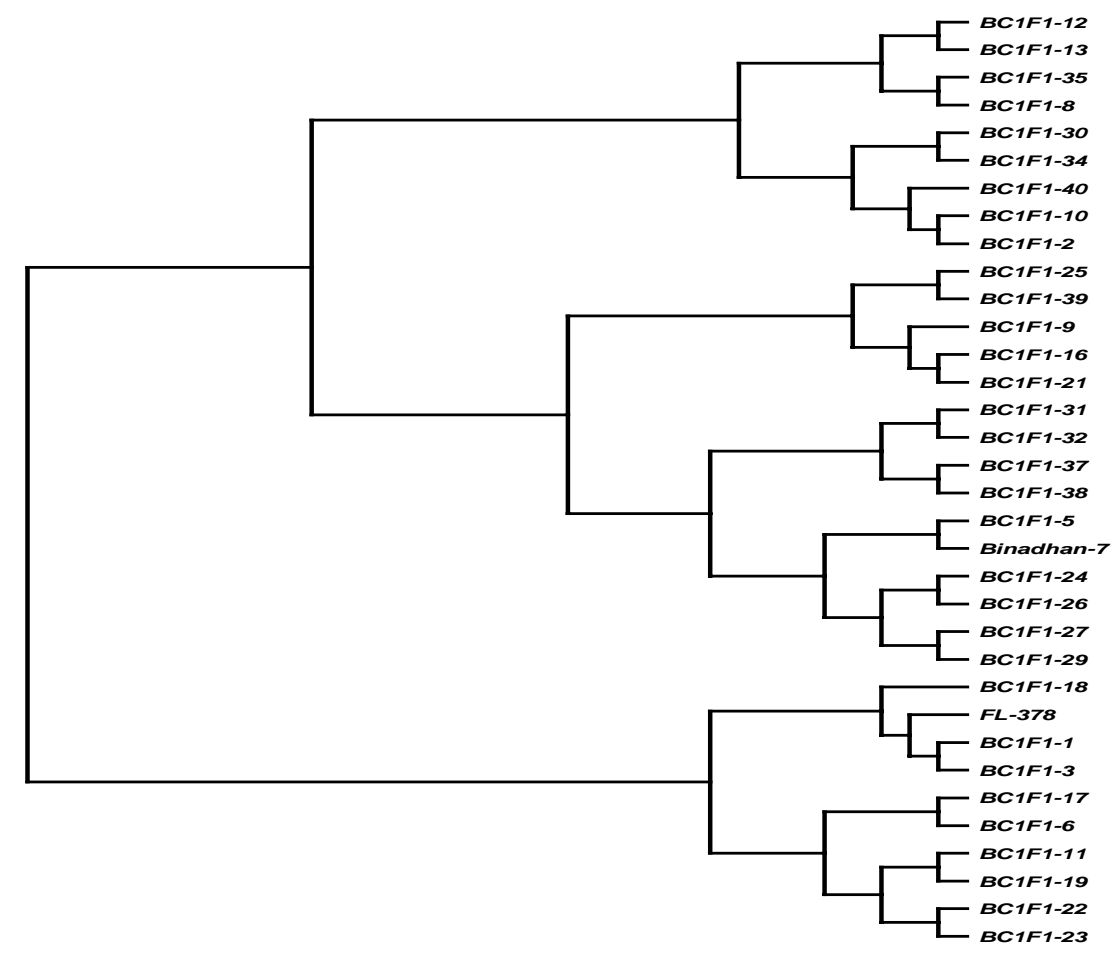

Fig. 4. A Dendrogram for $32 \mathrm{BC}_{1} \mathrm{~F}_{1}$ along with two parents derived from a UPGMA cluster analysis

\section{References}

ABSPII. 2006. Drought tolerant rice and salinity tolerance rice. Agricultural Biotechnology Support Project II- South Asia. 26.

Ashraf, M., Athar, H.R., Harris, P.J.C. and Kwon T.R. 2008. Some prospective strategies for improving crop salt tolerance. Adv. Agron. 97: 45-110.

Ashraf, M. 2009. Biotechnological approach of improving plant salt tolerance using antioxidants as markers. Biotech. Adv. 27: 84-93.

BBS. 2009. Bangladesh Bureau of Statistics. Crop Statistics (Major Crops). Agricultural Wing. Ministry of planing, Government of the Peaple's Republic of Bangladesh, Dhaka. 54. 
Bhuiyan, M.A.R. 2005. Efficiency in evaluating salt tolerance in rice using phenotypic and marker assisted selection. M.Sc. dissertation, Department of Genetics and Plant Breeding, Bangladesh Agricultural University, Mymensingh, Bangladesh. 96.

Chakravarthi, B.K. and Naravaneni, R. 2006. SSR marker based DNA fingerprinting and diversity study in rice (Oryza sativa L). Afr. J. Biotech. 5(9): 684-688.

El-Refaee, Y.Z., Atallah, M., Savo, M.L. and Porceddu, E. 2006. Fine QTLs mapping for salinity tolerance in rice. Proc. 50th Italian Soc. Agric. Genetics Annual Congress. Ischia, Italy. ISBN 88-900622-7-4. 10-14 Sep. 2006.

FAO. 2005. Mechanisms of salt tolerance: sodium, chloride and potassium homeostasis in two rice lines with different tolerance to salinity stress, http://bieson.ub.uni-bielefeld.de/volltexte/2006/873.

Gregorio, G.B. 1997. Tagging salinity tolerance genes in rice using Amplified Fragment Length Polymorphism (AFLP). Ph.D. Thesis, Univ. Philippines Los Banos. Laguna, Philippines.

Herrera, T.G., Duque, D.P., Almeida, I.P., Nunez, G.T., Pieter's, A.J., Martinez, C.P. and Tohme, J.M. 2008. Assessment of genetic diversity in Venezuelan rice cultivars using Simple Sequence Repeats markers electron. J. Biotech. 11(5): 215-226.

Islam, M.M. 2004. Mapping salinity tolerance genes in rice (Oryza sativa L.) at reproductive stage. Ph. D. dissertation. Univ. Philippines Los Banos, College, Laguna, Philippines. 1-149.

Litt, M. and Luty, J. A. 1989. A hypervariable microsatellite revealed by in vitro amplification of a di-nucleotide repeat within the cardiac muscle acting gene. Am. J. Hum. Genet., 44: 397-401.

Nei's, M. 1983. Analysis of gene diversity in subdivided populations. Proc. Natl. Acad. Sci. U.S.A., 70:3321-3323

Niones, J. M. 2004. Fine mapping of the salinity tolerance gene on chromosome 1 of rice (Oryza sativa L.) using near-isogenic lines. M.S. dissertation. Univ. Philippines Los Banos, College, Laguna, Philippines. 78.

Tautz, D. 1989. Hyper-variability of simple sequences as a general source for polymorphic DNA markers. Nucleic Acids Res., 36: 6463-6471.

Yu, K., Park, S.J. and Poysa, V. 2000. Marker-assisted selection of common beans for resistance to common bacterial blight: efficiency and economics. Plant Breed., 119: 411-415. 